\title{
Özofagus varis kanamasında kısa ve uzun süreli somatostatin infüzyon tedavisi sonuçlarının karşılaştırılması
}

Comparison of results in the short- and long-term treatment of somatostatin infusion for esophageal variceal hemorrhage

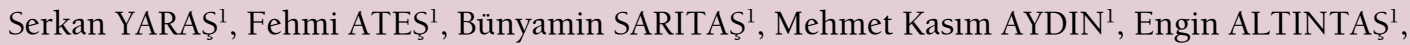
Gülhan ÖREKICI TEMEL ${ }^{2}$, Orhan SEZGIN ${ }^{1}$

Mersin Üniversitesi Tip Fakültesi ${ }^{1}$ Gastroenteroloji Bilim Dah, ${ }^{2}$ Biyoistatistik Anabilim Dalı, Mersin

Giriş ve Amaç: Vazopressin, Somatostatin ve bunların analogları (Terlipressin, Oktreotid) akut varis kanamalarında sıklıkla kullanılmaktadır. Bu ilaçlarin fayda ve riskleri ve özellikle de uygulanma süreleri açısından bir fikir birliği yoktur. Kliniğimizde Somatostatin uygulanan varis kanamalı hastalarda kısa ve uzun süreli Somatostatin uygulanmasının klinik etkinliği ile ilgili bir çalışma planladık. Materyal ve Metod: Bu amaçla 1 Ocak 2012-31 Temmuz 2012 tarihleri arasında özofagus varis kanaması nedeniyle yatırılan ardışı 39 hastaya sırasıyla kısa süreli (2 gün) veya uzun süreli ( 5 gün) Somatostatin infüzyonu 250 mikrogram/saat dozunda uyguland1. Her iki grup erken ve geç dönemde tekrar kanama, düzeltilmiş transfüzyon gereksinimi indeksi (Adjusted Blood Transfusion Requirement Index) skorları açısından karşılaştırıldı. Bulgular: Her iki grup yaş, siroz etyolojisi, Child Pugh ve MELD skoru açısından benzerdi. Düzeltilmiş transfüzyon gereksinimi indeksi, erken veya geç dönemde tekrar kanama sayısı, endoskopik tedavi sonrası optimal skleroze varis oranı açısından her iki grup arasında farklılık saptanmadı. (sırasıyla p=0,879, 0,411, 0,096). Sonuç: Çalışmamızda kısa süreli ve uzun süreli Somatostatin uygulanan iki grup arasında farklılık saptanmadı. Bu açıdan hem daha düşük maliyet hem de daha kısa süreli hastanede yatış gerektirdiğinden kısa süreli Somatostatin infüzyonunun daha kullanışlı olduğu sonucuna varılmıştır. Konuyla ilgili daha çok randomize çalışma yapılırsa kısa süreli infüzyon tedavisinin klinik uygulamalara yansıması mümkün olabilir.

Anahtar kelimeler: Kısa-uzun süreli somatostatin, varis kanaması
Background and Aims: Vasopressin, somatostatin and their analogs (terlipressin, octreotide) are used for acute variceal hemorrhage. There is no consensus about the benefits and risks of these drugs, especially in terms of the implementation period. In our clinic, we designed a study to evaluate the efficacy of somatostatin, in short- and long-term infusions. Materials and Methods: Thirty-nine consecutive patients with esophageal variceal hemorrhage treated with either short-term (2 days) or long-term (5 days) somatostatin infusion of 250 micrograms/hour, alternately, between January 1 and July 31, 2012 were included in the study. Both groups were compared in terms of the early and late rebleeding rates and Adjusted Blood Transfusion Requirement Index. Results: Both groups were similar in terms of age, cirrhosis etiology, and Child-Pugh and Model for End Stage Liver Disease scores. There were also no differences between the groups with respect to Adjusted Blood Transfusion Requirement Index, early and late rebleeding rates, and post-treatment optimal sclerosed varices rates ( $p=0,879,0,411$, 0,096, respectively). Conclusions: In our study, there was no difference between the two (short-term and long-term infusion) somatostatin groups. In view of the lower costs and shorter hospital stay, short-term infusion of somatostatin was concluded to be more useful than the long-term infusion. Clinical applications may be possible with further randomized trials relevant to this topic.

Keywords: Short- and long-term somatostatin, variceal bleeding

bant ligasyonu veya skleroterapiyi takiben 5 gün daha kullanılması gerektiği şeklindedir (3-5). Literatürde, Somatostatin infüzyonunun 48 saat yerine 120 saate kadar uzun süreyle uygulanmasının tedavi etkinliğine herhangi bir katkısı olmadığını ileri süren çalışmalar da vardır (6-8). Bu ilaçların fayda ve riskleri ve özellikle de uygulanma süreleri açısından bir fikir birliği yoktur. Kliniğimizde özofagus varis kanaması nedeniyle endoskopik bant ligasyonu sonrası Somatostatin uygulanan hastalarda kisa ve uzun süreli Somatostatin uygulanmasının (48 saat ve 120 saat) klinik etkinliğini karşılaştırmak amacıyla bir çalışma planlandı. 


\begin{tabular}{|c|c|c|c|c|}
\hline & & $\begin{array}{c}\text { Kısa Süreli } \\
\text { Tedavi } \\
\text { n }(\%)\end{array}$ & $\begin{array}{l}\text { Uzun Süreli } \\
\text { Tedavi } \\
\text { n(\%) }\end{array}$ & $\mathbf{p}$ \\
\hline Yaş & ort $\pm s s$ & $55,55 \pm 14,61$ & $53.26 \pm 11,78$ & 0,595 \\
\hline \multirow{2}{*}{ Cinsiyet } & Erkek & $13(65)$ & $10(52,6)$ & \multirow{2}{*}{0,433} \\
\hline & Kadın & $7(35)$ & $9(47,4)$ & \\
\hline \multirow{4}{*}{ Etyoloji } & HBV & $4(20,0)$ & $4(21,1)$ & \multirow{4}{*}{0,785} \\
\hline & $\mathrm{HCV}$ & $7(35)$ & $6(31,6)$ & \\
\hline & Alkol & $2(10)$ & $4(21,1)$ & \\
\hline & Kriptojenik & $7(35)$ & $5(26,3)$ & \\
\hline \multirow{2}{*}{ PHG } & Yok & $7(35)$ & $7(36,8)$ & \multirow{2}{*}{0,905} \\
\hline & Var & $13(65)$ & $12(63,2)$ & \\
\hline \multirow{2}{*}{ Fundal varis } & Yok & $15(75)$ & $12(63,2)$ & \multirow{2}{*}{0,423} \\
\hline & Var & $5(25)$ & $7(36,8)$ & \\
\hline CTP & Ort \pm ss & $7[6-8,75]$ & 7 [7-11] & 0,336 \\
\hline MELD & Ort \pm ss & $11[8,25-14]$ & 11 [10-17] & 0,550 \\
\hline \multirow{2}{*}{$\begin{array}{l}\text { Tekrar } \\
\text { kanama }\end{array}$} & Yok & $14(70)$ & $16(84,2)$ & \multirow{2}{*}{0,411} \\
\hline & Var & $6(30)$ & $3(15,8)$ & \\
\hline \multirow{2}{*}{$\begin{array}{l}\text { Optimal } \\
\text { skleroz }\end{array}$} & Yok & $18(90)$ & $19(100)$ & \multirow{2}{*}{0,096} \\
\hline & Var & $2(10)$ & $0(0,0)$ & \\
\hline ABRI & Ort \pm ss & $0,39[0-0,61]$ & $0,26[0-0,54]$ & 0,879 \\
\hline
\end{tabular}

PHG: Portal hipertansif gastropati, CTP: Child Turcot Pugh, MELD: Model for the End-stage Liver Disease, ABRI: Adjusted Blood transfusion Requirement Index

\section{MATERYAL ve METOD}

Mersin Üniversitesi Tip Fakültesi Hastanesi'ne 1 Ocak 201231 Temmuz 2012 tarihleri arasında başvuran ve özofagus varis kanaması nedeniyle yatırılan ardışı 39 hastaya Somatostatin infuzyonu 250 mikrogram/saat dozunda uyguland. Hastaneye ilk başvuru sırasında özofagus varis kanaması ön tanısı olan hastalar, her iki çalışma koluna (kısa ve uzun süreli: 48 saat veya 120 saat süreyle) hastane dosyalarının son rakamına göre randomize edildi. Hastalara acil servise başvuru döneminde endoskopik işlemi beklemeksizin 250 mikrogram Somatostatin intravenöz yoldan puşe olarak uyguland. Bütün hastalara çoklu bant sistemi ile özofagus varis bant ligasyonu uygulandi. Her iki grup erken ve geç dönemde tekrar kanama açısından karşılaştırıldı. ÖVK şiddetini belirlemek üzere, standardizasyonu sağlamak için Baveno IV Sempozyumunda kabul edilen ABRI (adjusted blood transfusion requirement index) formülü kullanıldı (9). Bu formülde ABRI =toplam ünite cinsinden yapılan transfüzyon sayısı/[(son hematokrit-ilk hematokrit)+0.01] şeklinde hesaplanan ABRI indeksi 0,75 ve üzerinde olursa kanamayı durdurmada başa- rısızlık söz konusudur. Istatistik hesaplamalarında anlamlı p değeri 0,05 olarak alındı.

\section{BULGULAR}

Her iki grup arasında yaş açısından (sırasıyla 55,55 14,61 yaşa karşılık 53,26 11,78 yaş, $\mathrm{p}=0,595)$ farklılık saptanmadı (Tablo 1). Siroz etyolojisi her iki grupta benzerdi $(p=0,785)$. Child Turcot Pugh puanı açısından iki grup arasında farklılik saptanmadı (sırasıyla 7 puana karşılık 7 puan, $\mathrm{p}=0,336$ ). Model for End Stage Liver Disease (MELD) skoru açısından her iki grup benzerdi (sırasıyla 11 puana karşılık 11 puan, $\mathrm{p}=0,550$ ). ABRI skoru, erken veya geç dönemde tekrar kanama sayısı, endoskopik tedavi sonrası optimal skleroze varis oranı açısından her iki grup arasında farklılık saptanmadı (sırasiyla $\mathrm{p}=0,879,0,411,0,096)$.

\section{TARTIŞMA}

Prospektif çalışmalar sirotik hastaların \%90'ından fazlasında hayatlarının bir aşamasında özofagus varisi geliştiğini göstermektedir. Siroz tanısı konulduğunda kompanse hastaların \%30-40'ında, dekompanse hastaların \%60'ında özofagus varisleri bulunur (10). Bir kez varis oluştuğunda, boyutu küçükten büyüğe doğru artar ve sonunda yırtılarak kanar. Küçük varisten büyük varis gelişimine ilerleyişi gösteren klinik çalışmaların sonuçları değişken olup yılda küçük varislerin \%5-30'u büyür (11-13). Somatostatin selektif olarak splanknik vazokonstrüksiyona yol açarak portal ven basıncını düşürür ve varis kanaması kontrolünde etkili olduğu gösterilmiştir $(1,5)$. Literatürde, ÖVK'da Somatostatin infüzyonunun 48 saat yerine 120 saate kadar uzun süreyle uygulanmasının tedavi etkinliğine herhangi bir katkısı olmadığını ileri süren çalışmalar vardır. Daha da ötesi, başarılı bir EBL sonrası adjuvan tedavi olarak sadece proton pompa inhibitörü infüzyonunun da, ilk hemostaz sonrası, erken tekrar kanama açısından vazoaktif ilaç uygulaması kadar başarılı sonuçlar verdiğini ve daha az yan etkiye yol açtığını ileri süren bir çalışma dahi mevcuttur (14). ÖVK tıbbi tedavisinde Somatostatin infüzyon süresinin 48 saat olması, uygulama kolaylığı, yan etkilerin ve ilaç maliyetinin azaltılması açısından bakıldığında daha elverişli gibi görünmektedir. Çalışmamızda ulaşılan sonuçlar kısa süreli Somatostatin infüzyonu lehinedir. Buna karşın literatürde uzun süreli infüzyonu öneren çok daha fazla çalışma, bu hipotezi desteklememektedir. Bizim hasta grubumuzun kısıtlı olması çalışmamızın zayıf yönlerinden biridir. Daha fazla sayıda hastanın katıldığı yeni çalışmalarla daha kesin sonuçlara ulaşılabileceği de açıktır. 


\section{KAYNAKLAR}

1. Bosch J, Kravetz D, Rodes J. Effects of somatostatin on hepatic and systemic hemodynamics in patients with cirrhosis of the liver: Comparison with vasopressin. Gastroenterology 1981;80:518-25.

2. Villanueva C, Colomo A, Aracil C, Guarner C. Current endoscopic therapy of variceal bleeding. Best Pract Res Clin Gastroenterol 2008;22:26178

3. de Franchis R; Baveno V Faculty. Revising consensus in portal hypertension: report of the Baveno $\mathrm{V}$ consensus workshop on methodology of diagnosis and therapy in portal hypertension. J Hepatol 2010;53:762-8.

4. Abraldes JG, Bosch J. The treatment of acute variceal bleeding. J Clin Gastroenterol 2007;41(Suppl 3):S312-7.

5. Burroughs A, McCormick P, Hughes MD, et al. Randomized, doubleblind, placebo-controlled trial of somatostatin for variceal bleeding Emergency control and prevention of early variceal rebleeding. Gastroenterology 1990;99:1388-95.

6. Avgerinos A, Nevens E Raptis S, Fevery J. Early administration of somatostatin and efficacy of sclerotherapy in acute oesophageal variceal bleeds. The European ABOVE randomised trial. Lancet 1997;350:1495-9.

7. Besson I, Ingrand P, Person B, et al. Sclerotherapy with or without octreotide for acute variceai bleeding. N Engl J Med 1995;333:555-60.
8. Romaozinho JM, Lopes H, Pontes JM, et al. Octreotide in the prevention of early rebleeding from esophageal varices. Comparing three dosage schemes [abstract]. Gastroenterology 1996;110:AI306.

9. de Franchis R. Evolving Consensus in Portal Hypertension Report of the Baveno IV consensus workshop on methodology of diagnosis and therapy in portal hypertension. J Hepatol 2005;43:167-76.

10. D'Amico G. Esophageal varices: froma aparence to rupture; natural history and prognosis indicators. In: Groszmann RJ BJ, ed. Portal Hypertension in the 21st Century. Dordrecht: kluwer Academic Publichers 2004:147-54.

11. Merli M, Nicolini G, Angeloni S, et al. Incidence and natural history of small esophageal varices in cirrhotic patients. J Hepatol 2003;38:26672 .

12. JB, JG A, JC GP. Clinical manifestations and management of bleeding episodes in cirrhotics. Textbook of Hepatology From Basic Science to Clinical Practice 2007;1:640-57.

13. Merkel C, Marin R, Angeli P, et al. A placebo-controlled clinical trial of nadolol in the prophylaxis of growth of small esophageal varices in cirrhosis. Gastroenterology 2004;127:476-84.

14. Lo GH, Perng DS, Chang CY, et al. Controlled trial of ligation plus vasoconstrictor versus proton pump inhibitor in the control of acute esophagealvariceal bleeding. J Gastroenterol Hepatol 2013;28:684-9. 